${ }^{\mathrm{I}}$ Universidade Federal do Rio de Janeiro (UFRJ)

Departamento de Sociologia, Brasil

antoniobrasiljr@gmail.com

Antonio Brasil Jr.'

\title{
AS IDEIAS COMO FORÇAS SOCIAIS: SOBRE UMA AGENDA DE PESQUISA ${ }^{1}$
}

Na produção intelectual de Elide Rugai Bastos, destacam-se dois planos distintos, embora interligados. Por um lado, em termos teórico-metodológicos, a análise da relação entre ideias e vida social é pensada como uma via de mão dupla, conjugando a reflexão sobre o lugar e os efeitos das ideias na constituição da sociedade brasileira e a análise de como as categorias empregadas pelos intelectuais acompanham o movimento mais amplo da sociedade. Por outro lado, sua atuação permitiu desdobrar esta perspectiva de análise na formação de algumas gerações de pesquisadores, não apenas a partir das pesquisas exemplares que desenvolveu, mas igualmente na presença cotidiana como orientadora, examinadora de bancas de qualificação e de defesa de teses e dissertações, debatedora em seminários e congressos, dentre outras atividades. ${ }^{2}$ Todos nós, em alguma medida, aprendemos a pesquisar e a refletir sobre o pensamento social no Brasil em diálogo com os trabalhos da autora. Por esta razão, vale a pena revisitarmos alguns de seus textos, hipóteses explicativas e protocolos de investigação empírica, seja para evidenciarmos a riqueza de seu percurso intelectual, seja para clarificarmos os desafios - que não são poucos - que sua perspectiva coloca para os novos pesquisadores.

Selecionei neste texto apenas os trabalhos da autora dedicados à chamada "escola sociológica paulista", isto é, a sociologia que se formou a partir de Florestan Fernandes. ${ }^{3}$ Se é verdade que este recorte torna a nossa tarefa mais fácil, isto não significa minimizar a complexidade deste universo textu- 
al, já que Bastos tem uma relação reflexiva muito sutil e refinada com a própria tradição intelectual na qual se formou. ${ }^{4}$ Ao analisar os textos de Florestan Fernandes, Octavio Ianni, Fernando Henrique Cardoso, além de José de Souza Martins, Fernando Novais - e também os trabalhos contemporâneos ancorados nesta perspectiva teórico-metodológica -, a autora não repisa os lugares-comuns assentados sobre Florestan Fernandes e seu grupo, nem os converte em simples objetos de pesquisa. Antes, ela mostra que as proposições teóricas ali contidas conformam uma sociologia crítica da sociedade brasileira. E, indo além desta afirmação, sugere que nesta sociologia crítica também se realizou um movimento no sentido de se repensar a teoria sociológica como um todo, cujos resultados são capazes de interpelar os horizontes de teorização contemporâneos. Noutras palavras, muito mais que pesquisar um objeto, Bastos também formaliza e sistematiza um conjunto de reflexões sobre uma potente perspectiva teórico-metodológica à qual criativamente se filia. Criativamente porque, conforme quero demonstrar ao final do texto, Bastos expande esta perspectiva a fim de torná-la plenamente comunicável às questões que a área de pesquisa em pensamento social vem elegendo como as mais significativas.

Em primeiro lugar, procurei delinear o meu referente empírico: quais são e quantos são os textos de Elide R. Bastos sobre Florestan Fernandes e seu grupo? Usando um critério lato, localizei quinze textos ligados direta ou indiretamente à "escola sociológica paulista" (Bastos, 20 I3, 20I I, 2009a, 2009b, 2004a, 2004b, 2002a, 2002b, 200I, I998, I996, I995, I99 I, I988, I987).

Identificando estes textos, podemos traçar melhor a posição ocupada por Bastos no conjunto dos intérpretes da produção sociológica de Florestan Fernandes e de seu grupo, completando e refinando os levantamentos bibliográficos que temos a este respeito até aqui, como o cuidadoso trabalho de Duarcides Mariosa (2007). Assim, usando um critério apenas quantitativo, já poderíamos localizar a autora no grupo dos mais prolíficos intérpretes, ao lado de, dentre outros, Gabriel Cohn, José de Souza Martins, Antonio Candido e Maria Arminda Arruda. Porém, esta dimensão está longe de ser a mais relevante. Este exercício de releitura procurará reter a importância deste conjunto textual em três pontos fundamentais. Em linhas gerais, identificamos nestes quinze textos:

i Uma compreensão bastante inovadora sobre a posição de Florestan Fernandes no processo mais geral de constituição das ciências sociais no Brasil;

ii Uma análise das categorias teóricas e dos princípios metodológicos que organizam os trabalhos de Florestan Fernandes e seu grupo - categorias e princípios que, segundo Bastos, se desdobram numa série de trabalhos até o presente; 
iii Uma reflexão sobre como Florestan Fernandes concebe o papel do intelectual numa sociedade como a brasileira. Dimensão que se articula, por sua vez, com uma das preocupações mais duradouras da autora em sua atuação como pesquisadora na área de pensamento social: a questão dos efeitos políticos das ideias e, no limite, da responsabilidade pública do homem de ideias.

Em nota de rodapé, no artigo sobre o "Pensamento social da escola sociológica paulista", Elide R. Bastos concorda com a seguinte afirmação de Gabriel Cohn:

[...] Gilberto Freyre forma com Florestan Fernandes o mais perfeito par de opostos que se possa imaginar. Não pela temática, que é em muitos pontos a mesma entre ambos. Nem pela formação e pelas linhas de pesquisa [...]. Mas pelo contraste entre a[s] [suas] perspectivas. (Cohn apud Bastos, 2002a: 2I5-2I6)

Imagino que os primeiros textos escritos pela autora sobre Florestan Fernandes e seu grupo tenham sido o resultado do esforço reflexivo de Bastos em contrastar Freyre e Fernandes durante a confecção de sua pesquisa de doutorado sobre o autor de Sobrados e mucambos (1936). Contraste que não passava pela disjuntiva "ensaio"/“ciência", 5 nem pelo recorte dado unicamente pela institucionalização universitária das ciências sociais, e, sim, pelas perspectivas muito diferenciadas a partir das quais os dois reconstroem a formação da sociedade brasileira. Se é verdade que Bastos concorda com Gabriel Cohn no sentido de explicar estas diferenças não somente na origem social de Freyre e Fernandes, mas especialmente no modo pelo qual os dois articulam os seus conceitos e métodos, ela vai além e busca situar o cerne de suas principais diferenças nos sentidos e nos efeitos políticos de suas ideias.

Assim, chama a atenção, no texto "Florestan Fernandes e a construção das ciências sociais", que está no livro Florestan Fernandes ou o sentido das coisas (I998), uma argumentação que localiza nos diferentes sentidos políticos assumidos pelas ideias as inflexões decisivas no processo de "sistematização" das ciências sociais no Brasil. A autora mobiliza a noção de "sistema", desenvolvida por Antonio Candido em Formação da literatura brasileira (I959), como forma de entender a história das ciências sociais não só em registro institucional, mas sobretudo no plano da circulação das ideias e de sua interação com as especificidades da sociedade brasileira. Para Bastos, é com Freyre que o discurso sociológico se configura como "sistema", processo obviamente que não começou com Casa grande \& senzala (I933) mas que, com ele, dá um salto qualitativo. Nos termos da autora:

É apenas na década de 20 que surgem os primeiros autores a tentar uma sistematização do pensamento que permita a elaboração de um referencial analítico da 
problemática social. Oliveira Vianna é um deles. Todavia, é somente com Gilberto Freyre, em sua obra de 30 , especificamente Casa grande \& senzala, que ocorre a transição. Em outros termos, esse trabalho representa um ponto de inflexão, o fechamento de um ciclo: marca o momento em que a teoria social deixa de apresentar-se como manifestação dispersa e surge como sistema. Nesse sentido, é o último pensador de um período e o primeiro de uma nova etapa. (Bastos, I998: I46)

Quer dizer: é com Freyre, na década de I930 - antes, portanto, da implantação universitária do ensino e da pesquisa em ciências sociais -, que se estabelece a autonomia explicativa do "social", se demonstra a "anticientificidade das intepretações racistas" e se faz a "crítica ao determinismo geográfico" (Bastos, 2009: I65). No entanto, o problema não se detém apenas na conformação de uma linguagem sociológica, posto que o decisivo é a análise de seus sentidos e efeitos da vida social mais ampla. ${ }^{6}$

Neste registro, qual a posição de Florestan Fernandes na construção das ciências sociais? Se a sociologia se "sistematiza" com Freyre, qual a especificidade do modo pelo qual Florestan Fernandes dá seguimento a esta "sistematização"? Justamente na crítica, inscrita na sociologia de Fernandes, ao modo pelo qual as ideias de Freyre (e outros autores anteriores) acabaram contribuindo para a reprodução dos arranjos tradicionais de dominação vigentes. Assim, a disjuntiva que polarizou este debate em torno do "ensaio" e da "ciência" perderia de vista aquilo que é essencial. Nas palavras da autora:

No final da década de 50 e início dos anos 6o, o acordo de quase 30 anos que formou o bloco agrário-industrial está sendo denunciado através de várias facetas da sociedade brasileira - pela crise do poder, pelos movimentos sociais, pelo desenvolvimentismo, pela retomada da questão dos direitos [...], pelo debate da questão fundiária, para citar alguns dos elementos presentes no processo. O pensamento social desenvolvido por Florestan soma-se a eles, contribuindo de modo efetivo para o questionamento do bloco no poder. Portanto, é natural que sua análise questione a Sociologia anterior, uma vez que a mesma não pensara a "verdadeira natureza" das relações sociais [...] E, nessa direção, critica as análises sociais fundadas unicamente sobre a diversidade - isto é, as explicações culturalistas da década de 30 , das quais resultaram as formulações sobre a democracia racial, indicadas como mito por Florestan Fernandes. Sua reflexão busca apontar que essa heterogeneidade esconde uma profunda desigualdade. Portanto, o debate sobre o âmbito da Sociologia não mostra um gratuito enfrentamento entre os autores, mas indica um profundo enraizamento no solo histórico onde se fundamentam as ideias. (Bastos, I999: I5O-I5I)

Esta passagem condensa os grandes temas de Bastos: os diferentes efeitos políticos das ideias, o papel dos movimentos sociais, dos conflitos e das crises sociais, econômicas e políticas na definição da "questão nacional" a ser enfrentada pelos intelectuais, a crítica à ideia de que diversidade e desigualdade sejam termos intercambiáveis, o enraizamento social das ideias e de sua gênese. E, o que é digno de nota, traça-se um programa de pesquisa sobre a história das ciências sociais no Brasil que não reduz o seu interesse somente 
aos conflitos internos ao campo universitário - ou aos debates estritamente intelectuais -, mas que coloca como decisivas as relações entre as ideias e as estruturas sociais em transformação histórica.7

Aliás, neste sentido, vale a pena abrir um parênteses e relembrar um dos primeiros textos de Bastos sobre Florestan Fernandes, intitulado "Um debate sobre a questão do negro no Brasil", publicado em I 988 na revista São Paulo em Perspectiva. Neste texto, ela nos lembra como os argumentos mobilizados por Roger Bastide e Florestan Fernandes sobre as causas e efeitos do "preconceito de cor" na sociedade brasileira não tinham surgido num vazio interpretativo, mas se ligavam diretamente à atuação dos movimentos negros em São Paulo, que reagiam em sua imprensa e em seus manifestos à visão tradicional sobre as relações raciais no país. Como, por exemplo, ao polêmico artigo de Paulo Duarte, intitulado "Negros do Brasil" (I 947), no qual o diretor da revista Anhembi lamentava, um tanto melancólico, a desaparição do "tipo tradicional do negro bom" (Duarte apud Bastos, I988: 2 I), isto é, do negro que "sabia o seu lugar".

Assim, a novidade da contribuição sociológica de Fernandes não residia apenas na crítica ao mito da "democracia racial”, uma vez que isto já era realizado "anteriormente pelos movimentos negros, pelo Teatro Experimental do Negro e por vários autores, como, por exemplo, Clovis Moura” (Bastos, 2009: I68). E, mesmo no plano da redação de A integração do negro na sociedade de classes (I 965), Bastos assinala que o livro, "que tem ao todo (são dois volumes) 655 páginas, dedica pouco mais de 16 páginas à crítica ao mito da democracia racial". Isto revelaria, portanto, que "a tese da obra é mais abrangente", uma vez que se tratava de "compreender como o mito da democracia racial funcionou como um dos elementos da manutenção, mesmo com a advento da República, de uma sociedade patrimonialista", isto é, como "mais um fator de resguardo por parte das velhas elites, das suas atribuições fundamentais na estrutura de poder da sociedade" (Bastos, 20I3: 273, itálicos no original). No limite, ela está sugerindo que, se devemos localizar um ponto crucial das discordâncias da "escola sociológica paulista" frente a Gilberto Freyre, este não reside, como muitos apontam, na questão das relações raciais per se, e sim na crítica, feita por Florestan Fernandes e por seu grupo na Universidade de São Paulo, aos limites impostos pela persistência do patrimonialismo na sociedade brasileira para a realização de relações sociais baseadas em direitos. Como assinala a autora:

Veja A integração do negro na sociedade de classes, em que o eixo da análise não se limita à questão racial, equívoco cometido por vários leitores dessa obra, embora a proposta original do programa de investigação junto a Roger Bastide tenha sido o "conhecimento sociológico sobre o preconceito racial no Brasil". Sem dúvida, na definição da situação da população negra e mulata, a raça é elemento dos mais importantes, base para que Florestan avalie os efeitos dos movimentos sociais a partir dele. Indo além do debate sobre a raça, o negro, no livro em pauta, ilustra a 
forma "como o povo emerge na história". Isto é, ao ocupar o posto desprivilegiado na sociedade, resultado das desvantagens históricas constituídas pela escravidão, torna-se objeto fundamental para analisar a inserção do povo na sociedade brasileira, marcada pela ambiguidade. (Bastos, 2002a: I9I)

Lembrando que, para Bastos, a questão central de Freyre tampouco era a interpretação de etnias e culturas, mas o papel do patriarcalismo na articulação da sociedade, ${ }^{8}$ vemos que o debate que ela reconstitui entre Freyre e Fernandes evidencia como os termos "patriarcalismo" e "patrimonialismo" apontam não só para distintas perspectivas teórico-metodológicas sobre a sociedade brasileira, mas também para os distintos efeitos políticos destas ideias. Com este procedimento, a autora mostra a possibilidade de se colocar em outra chave analítica o relacionamento das ciências sociais institucionalizadas em universidades e centros de pesquisa com os chamados "ensaios de intepretação nacional”. Afinal, para Bastos, o acerto de contas crítico feito pela sociologia de Florestan Fernandes e de seu grupo com o pensamento social anterior não se resumia ao "questionamento dessas interpretações" como fundamento de uma "busca de legitimação desses pesquisadores no campo intelectual". Antes, "a avaliação dessas tradições de pensamento tem um objetivo que se coloca além dessa intenção, pois se trata de um elemento intrínseco à proposta analítica" (Bastos, 2002a: I89).

Em suma, retomando a questão de "sistematização" da sociologia no Brasil, se pudermos tomar a década de I930 (com Freyre) e a de I950 (com Fernandes e seu grupo) como dois momentos fundamentais para a conformação da sociologia como um "sistema", a autora nos mostra que devemos completar esta abordagem, indo além da análise da interação dinâmica de autores, obras e públicos - "triângulo explicativo do processo sistematização da literatura brasileira", proposto por Antonio Candido, que explicitaria "a continuidade de uma tradição de pensamento" (Bastos, s/d: 6). Sem desconsiderar a importância decisiva destas linhas de continuidade entre o ensaísmo e as monografias científicas que surgiram a partir da institucionalização das ciências sociais, ${ }^{9}$ Bastos afirma que, "porém, para operar nesse campo creio ser necessário dar mais um passo que permita compreender como as ideias podem ancorar medidas políticas e, mesmo, a ossatura das instituições" (Bastos, s/d: 7). Este entendimento das ideias como forças sociais, que pauta a análise da autora sobre a história das ciências sociais no Brasil, também trará outros desdobramentos teórico-metodológicos cruciais que serão tratados mais adiante.

\section{II}

Uma vez explicitado o argumento de Elide R. Bastos sobre como devemos situar os trabalhos de Florestan Fernandes e de seu grupo no processo mais amplo de constituição das ciências sociais no Brasil - não tanto na afirmação da "ci- 
ência" vs. o "ensaísmo", mas no âmbito da crítica do bloco agrário-industrial que triunfou em I930 -, vale a pena destacar, rapidamente, o modo pelo qual a autora reconstrói as principais categorias e métodos de análise mobilizadas pela chamada "escola sociológica paulista". O uso desta denominação problemática se justificaria porque, segundo Bastos, os princípios cognitivos que orientam a análise de Fernandes não se limitaram a ele, mas se desdobraram em contribuições as mais diversas e que se estenderiam até hoje. ${ }^{\text {10 }}$ Abrindo mais um parêntese, e mais uma vez para contrastar Freyre e Fernandes: se o primeiro teve enorme dificuldade em "rotinizar" sua perspectiva analítica, posto que, no fundo, suas categorias de análise só com muita dificuldade se separavam de sua própria figura (com toda a mitologia do "gênio" aí envolvida), já o trabalho metódico de ensino e pesquisa de Florestan Fernandes na universidade teria possibilitado justamente a rotinização de sua perspectiva básica sobre o social (Bastos, 2002a: I89). Este talvez seja um dos principais efeitos da institucionalização universitária das ciências sociais, embora o resultado isto é, o fato de que a sociologia de Florestan Fernandes ainda persista como orientação teórico-metodológica de uma série de trabalhos - seja contingente. Assim, no texto em que discute com mais vagar as principais dimensões da teoria sociológica formalizada por Fernandes, "O pensamento social da escola sociológica paulista" (Bastos, 2002a), não estamos diante de uma simples reflexão sobre um "objeto", mas somos apresentados a um "método" capaz de alinhavar pesquisas sobre os mais diferentes aspectos da vida social. Em vez de "genialidade", do indivíduo excepcional, ${ }^{\text {II }}$ a possibilidade democrática da vida universitária no sentido de difundir e rotinizar o conhecimento. Não à toa, a epígrafe do artigo, que Bastos retira de Fernandes, diz justamente que "o trabalho da ciência enlaça as gerações sucessivas numa colaboração invisível e ininterrupta" (Fernandes apud Bastos, 2002a: I84).

Mas que perspectiva teórico-metodológica é esta? Segundo a autora, ela se ampararia nos seguintes pontos fundamentais (Bastos, 2002a):

a. O atraso como eixo: trata-se da recusa a uma visão dualista. Em vez de uma explicação linear dos processos, deveríamos buscar as articulações e os encontros entre o arcaico e o moderno;

b. A importância da história: o dinamismo que o capitalismo assumiu no Brasil não repetiu as experiências clássicas de revolução burguesa, tendo em vista a persistência da pobreza, da exclusão e da heterogeneidade;

c. A busca da totalidade: trata-se da recusa em se pensar a política separada da sociologia e da cultura, quer dizer, uma preocupação em não fragmentar o conhecimento da realidade social;

d. Importância das tensões e das crises sociais como articuladoras do conhecimento: em vez de se constituírem como "quebra da ordem", ou 
"anomia", as tensões e as crises teriam significação heurística, permitindo ver os fundamentos mais gerais da vida social, os nexos que, em situações de aparente "normalidade", estão encobertos.

Associando os quatro elementos colocados acima, a autora nos apresenta um padrão teórico-metodológico que buscaria, de acordo com a perspectiva compartilhada por Fernandes e seu grupo, preservar o conhecimento das especificidades da sociedade brasileira sem deixar de considerar o caráter "universal" das categorias que a sociologia emprega. Isto seria possível porque não se tomaria a "periferia" simplesmente como o lugar de análise, mas como uma forma de articular a totalidade na explicação sociológica. Nos termos de Bastos: "a partir da periferia percebe-se melhor o movimento da sociedade, possibilitando a verificação dos princípios que a estruturam" (Bastos, 2002a: I89, grifos no original). Neste registro, os dois principais trabalhos de Florestan Fernandes, A integração do negro na sociedade de classes (1965) e A revolução burguesa no Brasil (I975), exprimiriam esta perspectiva básica: por um lado, os limites da cidadania na sociedade brasileira como um todo seriam percebidos melhor através da análise do grupo que teve o pior ponto de partida na emergência da ordem social competitiva (os negros); por outro, a dissociação entre capitalismo e democracia cobraria maior nitidez na sociedade brasileira do que nos países que experimentaram uma revolução burguesa clássica. Como pontua a autora:

Aqui se coloca [...] a relação centro/periferia explicitada pela articulação parte/ todo, que atinge igualmente o negro e a sociedade. Em outros termos, a inclusão/ exclusão do negro opera como um "buraco negro" na sociedade brasileira, caracterizando sua incompletude em relação a um projeto realmente emancipatório. Nesse sentido, a análise funda uma crítica que se direciona às intepretações então correntes e às categorias cunhadas para dar conta da vivência da desigualdade. A posição desses agentes não pode ser vista em termos de marginalização, proposta analítica presente em grande parte das discussões sobre a América Latina e de sua situação de subdesenvolvimento. Ademais, aponta para as restrições das análises fundadas apenas sobre a diversidade [...]. (Bastos, 2002a: I92, grifos no original)

Imagino que esta forma de reconstruir a perspectiva teórico-metodológica legada por Fernandes possa explicar por que, para Bastos, esta tradição possuiria enormes afinidades com outras florações do pensamento crítico, especialmente de certas versões do marxismo gestadas em contextos periféricos ou historicamente problemáticos. Em especial, refiro-me a Georg Lukács e Antonio Gramsci, autores constantemente mobilizados pela autora em suas reflexões. ${ }^{\mathrm{I2}} \mathrm{A}$ respeito de Lukács, parece ser decisivo, para Bastos, o conjunto de textos sobre a literatura alemã, como os reunidos em Nueva his toria de la literatura alemana (I97I), em que o autor húngaro analisa a questão do protagonismo dos intelectuais e suas ambiguidades diante de um processo de modernização tardio. Aliás, esta discussão parece ter orientado parte das 
reflexões da autora sobre as ciências sociais no país. Retomando a discussão de que Freyre e Fernandes se situam "em posições opostas tanto em termos de ideias como em relação ao efeito social que as mesmas assumem", completa:

A crítica que Florestan Fernandes faz a Gilberto Freyre tem a ver com a mesma preocupação levantada por Lukács sobre a reconstrução da história fundada em forte fantasia sobre o passado e as origens da formação nacional como obstáculo à ação positiva de uma base social. Ao apontar para a fabulação construída por Freyre em relação à existência no Brasil de uma democracia racial, seu interesse centra-se na denúncia dessas ideias que se configuram como impedimento a que os negros, no Brasil, até um certo momento da história, tentem recusar solução associativa para seus problemas e busquem para eles uma solução individual. Isto é, essa visão edulcorada da sociedade brasileira opera como fonte de paralisação ao desempenho político dos negros (Bastos, s/d: 20, grifos no original).

Ainda no que toca a Lukács, ela assinala que é possível ver entre o autor húngaro e Florestan Fernandes uma certa convergência, já que ambos considerariam a centralidade da "crise" como ferramenta heurística, isto é, como meio privilegiado para se apanhar o movimento da sociedade em seu conjunto (Bastos, 2002a: 209).

Já em relação a Gramsci, Bastos diz que há uma aproximação entre a maneira pela qual o autor italiano encaminha sua análise sobre a "questão meridional" - entendida como uma visão sobre o conjunto da sociedade italiana, e não apenas sobre o Sul -, e a perspectiva de Fernandes, que vê virtudes heurísticas na periferia quando se trata de perceber o movimento do "todo". Numa nota de rodapé de seu texto sobre a "escola sociológica paulista", ela sugere, no entanto, que o autor de A revolução burguesa no Brasil (I975) vai além de Gramsci:

Penso que no caso de Gramsci a referência maior está na questão nacional. Assim, para esse autor a proposta é pensar a emancipação do Sul como um momento necessário da emancipação da Nação. Na proposição de Florestan Fernandes o problema está ampliado, abarcando a compreensão da dependência do país ao centro hegemônico da economia. (Bastos, 2002a: 189)

Vemos, pois, um esforço notável de desprovincianização do "pensamento social" feito no Brasil, já que Bastos situa a "sociologia crítica" de Florestan Fernandes numa cartografia ampliada de uma certa perspectiva do marxismo - quando digo situar não digo "encaixar", pois ela sempre realça como o autor precisou lidar com várias perspectivas teóricas diferentes a fim de entender a pluralidade dos conflitos sociais que se apresentam na sociedade brasileira (Bastos, 20 I : 67). Além disto, haveria uma dimensão normativa na reflexão da "escola sociológica paulista" que coloca no centro da análise as questões referidas à emancipação humana, orientando as investigações no sentido de inquirir as razões pelas a sociedade brasileira frustra de modo estrutural a realização das promessas emancipatórias da modernidade:I3 
As pesquisas referidas não apontam apenas para o não cumprimento dessas promessas, o que não seria original se considerada a reflexão sociológica contemporânea, mas voltam-se à indagação tanto sobre os limites como os efeitos dessa realização na sociedade brasileira. Em outros termos, a essa tradição de pensamento não é suficiente a afirmação da não realização das promessas e a indicação das formas que assume esse não cumprimento. É necessário indagar o porquê dessa situação e apontar os limites que a sociedade brasileira coloca a esse projeto. Em suma, quais os efeitos dessa irrealização, ou seja, qual a sociedade resultante do processo? (Bastos, 2002a: 224)

Antes de fechar esta seção do trabalho, queria chamar a atenção para mais um ponto. Embora sem minimizar o problema, Bastos não interpreta os trabalhos de Florestan Fernandes realçando alguma ideia de corte radical epistemológico, político, institucional etc. - entre a sua produção anterior e posterior ao golpe de I964 e suas consequências na universidade. Muito pelo contrário, ela vê mesmo naqueles textos entendidos convencionalmente como amparados numa sociologia acadêmica, de perfil funcionalista, a formalização de uma perspectiva crítica dos processos sociais.

Este aspecto está bastante claro num texto em que a autora discute o conjunto da produção da USP sobre relações raciais entre I950 e I960, embora se concentre mais nas proposições de Octavio Ianni. ${ }^{14}$ Discordando da tipologia de fases proposta por Enno Liedke Filho (I977) - creio que a tipologia de Liedke Filho seja uma ilustração; outras poderiam ser igualmente aventadas -, argumenta Bastos:

Creio ser possível questionar essas afirmações, uma vez que várias categorias empregadas pelos autores - como, por exemplo, ordem social competitiva, noção nuclear articulada à categoria estrutura de classes - não se restringem aos limites do conceito ordem social, suporte da ideia de demora cultural. Ou ainda, a vinculação questão racial/questão nacional, pela sua própria formulação, ultrapassa aqueles limites. (Bastos, I996: 82)

[...] Ultrapassando as barreiras impostas pela tese da demora cultural, mostrando que existem elementos totalizadores da explicação e que não é por acaso que as diferentes esferas do social desenvolvem-se de forma descompassada, essa pesquisa lança as bases para um novo patamar de reflexão [...]. (Bastos, I 996: 90)

Nesse sentido, a reflexão a respeito dos estudos de Octavio Ianni sobre a questão racial, articulada à questão nacional, mostra a impossibilidade de constituição de uma tipologia estática. (Bastos, I996: 82)

Dito de outro modo, mesmo naqueles trabalhos à primeira vista aparentados a uma perspectiva funcionalista seria possível ver inovações decisivas para uma compreensão renovada não apenas da questão racial, mas da própria teoria sociológica. Daí que Bastos veja na combinação das duas principais teses de Fernandes, "sobre o negro e sobre a revolução burguesa", uma "ruptura crítica com a reflexão sociológica anterior", podendo-se afirmar que haveria 
"uma continuidade nessas duas temáticas da obra de Florestan Fernandes", ambas assinalando para um "processo de transformação da moderna sociedade brasileira" que se mostraria compatível com "a exclusão social, econômica e política das classes subalternas" (Bastos, I998: I52).

No entanto, Bastos não desconsidera a questão das diferentes fases da produção de Florestan e seu grupo. O ponto que ela levanta é que não podemos operar com uma tipologia estática e estanque de classificação. Esta advertência é importante porque ela sempre alertou para as diferenças existentes, por exemplo, entre os dois prefácios de A sociologia numa era de revolução social (escritos em I962 e I976, respectivamente), nos quais há uma inflexão no modo pelo qual Fernandes vê as possibilidades de participação do sociólogo na sociedade (Bastos, I998: I53; 2002a: 202). Esta questão, legada pela "escola sociológica paulista" - a da "missão" do sociólogo numa sociedade periférica -, será trabalhada de maneira criativa pela autora em suas reflexões mais amplas sobre o protagonismo dos intelectuais e dos efeitos do trabalho intelectual na articulação das forças sociais que movem a sociedade brasileira.

\section{III}

Em resenha a Destino ímpar: sobre a formação de Florestan Fernandes (2002), de Sylvia Garcia, Elide R. Bastos, ao lado de reconhecer os muitos méritos do livro, faz uma indagação muito significativa. Localizando o argumento do livro num quadro mais geral de narrativas de "formação", no registro europeu do termo, ela aponta para o seguinte problema:

Diferentemente dos modelos europeus clássicos, no Brasil o alvo prioritário da formação não é apenas o indivíduo, mas também a nação, e o motivo dessa duplicidade reside na "incompletude da revolução burguesa", para usar expressão de Florestan. Assim, a ampliação da temática desenvolvida demandaria pensar não somente as transformações de São Paulo, mas ter como referência a questão nacional. Essa aproximação permitiria refletir mais amplamente a respeito do papel do intelectual formulado pelo próprio Florestan. O encaminhamento da questão nacional é definidor dos temas que o preocupam e que se tornam centrais em suas formulações. [...] [Neste sentido,] [o] ponto central é o questionamento do modo como se processa a formação, pois, diferentemente dos países centrais, no Brasil a educação não pode estar voltada somente para o conhecimento da modernidade. A realização desta supõe não só o conhecimento dos elementos tradicionais presentes na sociedade brasileira, mas a compreensão do imbricamento dos dois polos na constituição das relações sociais, na configuração da própria realidade. É nesse sentido que o sociólogo paulista se propõe a trabalhar em conjunto as diferentes teorias para chegar a uma síntese e a enfocar um método capaz de formar pesquisadores. (Bastos, 2002b: 2).

Mais uma vez, acredito que na passagem acima se condensam vários dos pontos fundamentais da reflexão da autora. Mas queria reter aqui o modo pelo qual ela assinala o deslocamento da temática da "formação" do indivíduo 
para a "formação" da nação, já que os dois termos desta relação seriam problemáticos e precisariam ser repensados em virtude da "incompletude da revolução burguesa". Não se trata, no que toca a este problema, nem de idiossincrasia de Florestan Fernandes, ${ }^{15}$ nem de uma autodescrição voluntarista no sentido da "missão" do intelectual que precisaria "formar", isto é, dar uma "forma", à sociedade em que atua (ver, por exemplo, Pécaut, I990). E tampouco uma simples racionalização da atividade intelectual com o propósito de encobrir seus interesses materiais e ideais nas estruturas vigentes de poder, em processo de diferenciação e divisão do trabalho político (ver, por exemplo, Miceli, 200I).

O ponto para o qual Bastos nos chama a atenção é que a sociedade brasileira possui certas especificidades históricas que redefinem o lugar e o papel dos intelectuais, dando-lhes certo protagonismo. Não se trata de repisar os pressupostos mannheimianos da noção de intelligentsia, em parte incorporados pelo próprio Florestan Fernandes, mas de mostrar que, concordando com um argumento de Gildo Marçal Brandão, "não temos uma história feliz e os países que não as têm costumam delegar muito a seus intelectuais" (Brandão apud Bastos, 2002a: 225). Este protagonismo se expressa, evidentemente, de modo muito diferenciado em cada momento histórico, porque, nos lembraria Bastos (s/d: I2-I3), são diferentes as temáticas que definem a questão nacional em cada contexto e também são diferentes as correlações das forças sociais vigentes. Aliás, é por esta entrada que ela entende a importância da área de pesquisa em pensamento social. Estudamos o "pensamento social no Brasil" não somente porque queremos compreender a dinâmica interna das atividades dos homens e mulheres de ideias (vistas seja por um ângulo contextualista ou textualista), mas justamente porque, sem entender como as ideias se convertem em forças sociais, não podemos analisar o movimento mais amplo da sociedade. Ora, se isto é uma posição teórico-metodológica a respeito da vida social em geral, no caso de um contexto como o brasileiro - que repõe permanentemente o problema do protagonismo dos intelectuais - levar isto em conta seria absolutamente central. Esta questão foi colocada logo no começo de seu texto sobre a "escola sociológica paulista":

Certa vez, ao lado de um colega, grande especialista em pensamento brasileiro, ouvi de um sociólogo estrangeiro a pergunta: por que vocês, no Brasil, se preocupam tanto em estudar seus próprios autores? Deixando de lado a sugestão, embutida no questionamento, sobre a "fraqueza teórica" dos mesmos, o que "explicaria" sua pouca importância, tentamos explicar-lhe que sem compreender tanto as ideias quanto o lugar desses intelectuais é impossível apreender o movimento geral da sociedade brasileira. (Bastos, 2002a: I83)

Este é o modo pelo qual, a meu ver, Bastos equaciona uma questão básica legada pela tradição sociológica de Florestan Fernandes e a relaciona com a área de pesquisa em pensamento social. Como ressaltou a autora em várias ocasiões, para Fernandes não bastava apenas ao sociólogo brasileiro compre- 
ender a sua própria sociedade, mas também atuar no sentido de transformar a sociologia num meio de "educação para a democracia", ou, nos termos de sua sociologia aplicada - até hoje tão pouco compreendida -, de forjar "personalidades democráticas" ajustadas à racionalidade exigida por um presente em transformação. Embora esta posição carregue uma clara dimensão normativa, já que acena para "uma posição marcada pela responsabilidade intelectual ativa, crítica e militante" (Bastos, I 998: I55), ela não deixa de colocar como fundamental a pergunta sobre a efetividade social das ideias. E aquela inflexão que Bastos localiza entre os dois prefácios de A sociologia numa era de revolução social teria a ver justamente com a compreensão de Fernandes de que, no pósI964, tinham se evidenciado os limites de sua tentativa de transformar a sociologia numa espécie de "autoconsciência científica da sociedade". Isto significa que, entre outros motivos, outras interpretações do país que, ao contrário da "sociologia crítica" que se gestou a partir de Florestan Fernandes, desacreditavam das instituições democráticas e das instâncias de auto-organização das camadas subalternas continuavam enformando a cultura política do país e se corporificando institucionalmente.

Noutras palavras, a fim de entendermos os limites do projeto emancipatório no Brasil - a "incompletude da revolução burguesa" -, não podemos deixar de entender o porquê de certas interpretações terem tido mais êxito que outras em se transformarem em forças sociais efetivas. Daí que a recorrência das pesquisas de Bastos sobre os autores conservadores e/ou autoritários não seja questão de preferência, mas de diagnóstico sociológico. Esta questão se explicita, por exemplo, em seus trabalhos sobre Luís Amaral (Bastos, 2008) e sobre Paulo Augusto Figueiredo (Bastos, 2006b), nos quais demonstra que a análise sobre autores considerados "menores" permite apanhar com muito mais clareza a conformação do léxico intelectual de um período e o grau de difusão de determinadas ideias na explicação dos dilemas a serem enfrentados social e politicamente.

Em suma, e aqui chegamos ao último ponto deste texto, é assim que Elide R. Bastos, de maneira bastante criativa e reflexiva, se filia à tradição sociológica da "escola paulista". Criativa e reflexiva porque ela mesma assinala que esta tradição teria deixado "de lado em sua reflexão alguns elementos importantes", como a "discussão sobre os caminhos da institucionalização das ideias, da constituição dos grupos intelectuais [...] ou da formulação do léxico que funda as instituições sociais e políticas" (Bastos, 2002a: 224). A autora procurou, portanto, estender a perspectiva da "escola sociológica paulista" para além de seus limites, mostrando como ela ainda pode ser potente para pensarmos os lugares e os efeitos das ideias na conformação da sociedade brasileira, o que, de modo algum, a faz desconhecer as enormes dificuldades desta posição para as atividades de pesquisa, pois ainda precisamos avançar muito no entendimento de como as ideias efetivamente se transformam em 
forças sociais concretas no desenho da sociedade. Isto nos coloca como tarefa crucial entender como a sociedade se articula em seu conjunto; ao mesmo tempo, isto nos força, comparativamente, a entender as razões pelas quais tanto as ideias quanto os intelectuais têm pesos diferentes de acordo com as especificidades históricas em jogo.

Eis o tamanho do desafio que o trabalho de Bastos impõe àqueles que queiram se arriscar a pesquisar as ideias e suas formas de articulação na sociedade. Isto envolve, necessariamente, ir na contramão das tendências à especialização e à fragmentação do conhecimento do social, já que, sem uma perspectiva de totalidade, não podemos entender, ao fim e ao cabo, a pergunta crucial sobre os efeitos sociais e políticos das ideias.

Recebido em I4/05/20I5 | Aprovado em 02/08/20I5

Antonio Brasil Jr. é professor adjunto do Departamento de Sociologia da Universidade Federal do Rio de Janeiro (UFRJ). Professor do Programa de Pós-graduação em Sociologia da Universidade Federal Fluminense (PPGS/UFF). É autor do livro Passagens para a teoria sociológica (2013). 


\section{NOTAS}

I Este texto é uma versão revista e ampliada da comunicação apresentada no $2^{\circ}$ Seminário de Pensamento Social, organizado em novembro de 2013 pela rede de pesquisadores da Biblioteca Virtual do Pensamento Social, realizado no Instituto de Filosofia e Ciências Sociais da Universidade Federal do Rio de Janeiro.

2 Uma rápida consulta aos dados de Elide Rugai Bastos compilados pela base Stela Experta (em maio de 20I5), que reúne informações disponíveis no CV-Lattes, dá um pouco da dimensão da produção da autora: 32 artigos em periódicos, 40 capítulos de livros, 6 livros publicados e 7 organizados; orientação de 3 I dissertações de mestrado e 2I teses de doutorado; I98 participações em bancas de trabalhos de conclusão. Em termos gerais de produção intelectual, desde i 996 - ou seja, há quase 20 anos -, Bastos vem produzindo I 9 itens ou mais por ano, com picos de 57 itens (2000) e 40 itens (2010 e 20I2).

3 Ainda que a autora tenha empregado este termo ao seu trabalho de 2002, "Pensamento social da escola sociológica paulista”, ela mesma aponta para o caráter problemático desta designação, pois "é importante ressaltar que, na definição da Sociologia como disciplina em São Paulo, estão presentes vários outros intelectuais, tanto da Universidade de São Paulo quanto da Escola de Sociologia e Política. No caso de Florestan Fernandes, seus assistentes e alunos, acentuo o caráter coletivo da produção e influência de suas ideias em textos posteriores" (Bastos, 2002a: I84-I85).

4 Em sua resposta à polêmica aberta por Roberto Motta, a respeito da interpretação que Elide R. Bastos fez da obra de Gilberto Freyre, a autora localiza suas próprias posições da seguinte maneira: "Assim, concordo com a afirmação de Roberto Motta de que minha leitura tem endereço conhecido - pertenço a uma tradição interpretativa que tem sua base na Faculdade de Filosofia e Ciências Humanas da Universidade de São Paulo (aliás, não apenas no curso de Ciências Sociais da USP, como sugere)” (Bastos, 2009: I64).

5 "Primeiramente, quero assinalar que recuso a visão assumida por alguns críticos, que consideram o ensaio como uma forma menor, pré-científica, genérica, por isso desti- 
tuída de poder explicativo. Sinto-me liberada de discutir a questão, uma vez que o texto de Theodor Adorno, 'O ensaio como forma', já colocou os argumentos necessários à crítica dessa posição, argumentos, aliás, que considero indispensáveis para exorcizar certa visão cartesiana que em certo momento invadiu algumas áreas das ciências sociais" (Bastos, s/d: Io).

6 Elide R. Bastos não considera Gilberto Freyre o único a realizar a crítica às teses racistas que vinham balizando o debate sobre a sociedade brasileira até então. E tampouco ignora que a dimensão biológica continuaria a ser um elemento importante na reflexão do autor de Casa grande \& senzala (I933). A seu ver, o privilégio explicativo dado à vida social teria um sentido preciso: "Gilberto Freyre, ao colocar sob outra luz a questão, permite o equacionamento do problema em outro patamar. A raça vista como um 'problema', um obstáculo à integração, perde sua força. A redefinição do problema passará pela discussão do regionalismo e ao papel desempenhado pelo patriarcado na gênese e consolidação da sociedade brasileira" (Bastos, 2006a: 76).

7 Neste sentido, Elide R. Bastos se mostra contemporânea a uma série de perspectivas teóricas, como as de Anthony Giddens (2013) e de Niklas Luhmann (2007), que valorizam a relação entre ideias e sociedade numa via de mão dupla, isto é, não só a conformação social das ideias - como aponta a sociologia do conhecimento mais usual -, mas igualmente os efeitos sociais das ideias na conformação de imagens de mundo, de desenhos institucionais e de práticas sociais. Para uma análise desta problemática, ver Botelho (2012).

8 "[...] ousei afastar-me do debate que afirma estar na questão da articulação das etnias e culturas o eixo da interpretação de Gilberto. A ênfase dada à contribuição cultural das três raças formadoras na constituição da sociedade brasileira é, inegavelmente, um passo gigante em relação às interpretações anteriores. Talvez essa importância, aliada ao fato de negar a inferioridade das raças não brancas, tenha ajudado a obscurecer o tema que aponto como tese principal que preside o conjunto de suas obras, isto é, a afirmação do papel do patriarcado na construção desse amálgama racial e cultural" (Bastos, 2009: I67). 
9 Elide R. Bastos também chama a atenção que a crítica ao "patriarcalismo" como categoria explicativa para o conjunto da sociedade brasileira já havia sido feita por Sergio Buarque de Holanda. "Creio que, neste mesmo ponto, se apoia a principal controvérsia do denominado 'grupo us piano' com Gilberto Freyre. Aliás, não apenas com ele, mas com Oliveira Vianna, Nestor Duarte e Fernando de Azevedo. Trata-se de questionar a unilateralidade da análise desses autores gerada pela 'redução do macrocosmo social inerente à ordem estamental e de castas ao microcosmo inerente à plantação ou ao engenho e à fazenda'. Florestan propõe, assim, uma análise sociológica que mostre que 'a economia de plantação faz parte de um contexto histórico estrutural e inclusivo e determinante; o problema central não consiste em explicar um ou outro, mas ambos'. Em outros termos, a análise passa a levar em consideração simultaneamente o processo que explicita as relações sociais - o patrimonialismo - e o ator que induz essas relações, o patriarca" (Bastos, 2013: 275). Noutro texto, a autora também salienta a importância de Caio Prado Jr. para os trabalhos da "escola sociológica paulista" (Bastos, 2002a: 207).

Io No texto "Pensamento social da escola sociológica paulista", Elide R. Bastos (2002a) analisa não apenas alguns trabalhos já considerados clássicos, como os de Florestan Fernandes e de seus assistentes e orientandos na Cadeira de Sociologia I da Universidade de São Paulo, mas ressalta também a presença de seus princípios teórico-metodológicos em trabalhos contemporâneos.

I I Sobre a questão da "genialidade" de Gilberto Freyre, Elide R. Bastos desloca a questão para um âmbito que, para ela, seria o mais decisivo: "A resposta poderia limitar-se, como já havia sido dada por vários autores, à sua inegável genialidade. Embora sem dúvida esta qualidade seja essencial, o domínio de um novo instrumental analítico pareceu-me importante para que ele desse um grande passo na análise da realidade brasileira" (Bastos, 2009: 165).

I 2 Um terceiro autor que poderia ser mencionado é Lucien Goldmann. Como Elide R. Bastos já se referiu em algumas oportunidades, seu livro Le Dieu caché (I955), uma investigação sobre a tragédia em Pascal e Racine, foi uma referência fundamental em sua pesquisa sobre Gilberto Freyre 
570

(ver Bastos, 2006a), aparecendo também fortemente em seu trabalho sobre Octavio de Faria (ver Bastos, 2010).

I3 Para Elide R. Bastos (20I I: 59), esta dimensão ética presente na reflexão de Florestan Fernandes o aproxima das discussões contemporâneas da teoria sociológica, "principalmente quando os problemas da identidade e possibilidade de reivindicação de direitos são abordados pelas teorias do reconhecimento".

I4 Trata-se do texto que ela redigiu para as Jornadas de Marília sobre Octavio Ianni, cujos trabalhos estão reunidos em Humanismo e compromisso (I996).

I5 Como é patente em seu trabalho sobre a "escola sociológica paulista", Elide R. Bastos demonstra a pertinência contemporânea do partido teórico-metodológico de Florestan Fernandes fazendo referência a uma série de trabalhos recentes que estariam ancorados nesta tradição intelectual. Em relação a tema da "formação" em contextos periféricos, a autora comenta o trabalho de André Botelho (2002) sobre o livro Através do Brasil (igro), de Manoel Bomfim e Olavo Bilac: "Diferentemente daqueles que buscam definir para o indivíduo os papéis sociais a serem desempenhados na sociedade, no Brasil, o objeto é a nação, como sujeito do processo de formação. É por isso que, segundo o autor, se coloca no país, em outros moldes, a função dos intelectuais. A análise desmistifica, passo a passo, a crença de que os intelectuais desempenham uma missão pedagógica de redenção do atraso brasileiro" (Bastos, 2002a: 218). 


\section{REFERÊNCIAS BIBLIOGRÁFICAS}

Bastos, Elide R. (2013). Gilberto Freyre e Florestan Fernandes: um debate sobre a democracia racial. In: Motta, Roberto \& Fernandes, Marcionila (orgs.). Gilberto Freyre: região, tradição, trópico e outras aproximações. Rio de Janeiro: Fundação Miguel de Cervantes, p. 262-278.

Bastos, Elide R. (20I I). Atualidade do pensamento social brasileiro. Sociedade e Estado, 26/2, maio/ago., p. 5I-70.

Bastos, Elide R. (20I0). Octavio de Faria e a tragédia burguesa. In: Ferreira, Gabriela N. \& Botelho, André (orgs.). Revisão do pensamento conservador: ideias e política no Brasil. São Paulo: Hucitec, p. 273-310.

Bastos, Elide R. (2009). América Latina, um compromisso. In: Iamamoto, Marilda Villela \& Behring, Elaine Rossetti (orgs.). Pensamento de Octavio Ianni: um balanço de sua contribuição à interpretação do Brasil. Rio de Janeiro: 7 Letras, p. I89-I94.

Bastos, Elide R. (2009). Octavio Ianni: diversidade e desigualdade. In: Botelho, André \& Schwarcz, Lilia Moritz (orgs.). Um enigma chamado Brasil. 29 intérpretes e um país. São Paulo: Companhia das Letras, p. 378-398.

Bastos, Elide R. (2008). O outro Brasil de Luís Amaral. In: Botelho, Andre; Bastos, Elide R \& Villas Bôas, Glaucia (orgs.). O moderno em questão: a década de I 950 no Brasil. Rio de Janeiro: Topbooks, p. 27-64.

BASTOS, Elide R. (2006a). Criaturas de Prometeu: Gilberto Freyre e a formação da sociedade brasileira. São Paulo: Global. Bastos, Elide R. (2006b). Paulo Augusto Figueiredo e o pensamento autoritário no Brasil. In: Ridenti, Marcelo; Bastos, Elide R. \& Rolland, Dennis (orgs.). Intelectuais e estado. Belo Horizonte: Ed. UFMG.

Bastos, Elide R. (2004). Referência ética e intelectual. Estudos de Sociologia, I6, p. I73-I78.

Bastos, Elide R. (2004). Ianni, a responsabilidade intelectual levada ao limite. Jornal da UNICAMP, Campinas, p. 4, I9 de abril.

Bastos, Elide R. (2002a). Pensamento social da escola sociológica paulista. In: Miceli, Sergio (org.). O que ler na ciên- 
cia social brasileira: 1970-2002. São Paulo/Brasília: Sumaré/ ANPOCS, p. I83-230.

Bastos, Elide R. (2002b). O jovem Florestan. Jornal de Resenhas/Folha de S. Paulo, São Paulo, p. 2, Io de agosto.

Bastos, Elide R. (200I). Gilberto Freyre et Florestan Fernandes: un débat sur les sciences sociales au Brésil. Sur le Brésil contemporaine. Paris: Centre de Recherches sur le Brésil Contemporaine, p. Di-Di7.

Bastos, Elide R. (I998). Florestan Fernandes e a construção das ciências sociais. In: Martinez, Paulo Henrique (org.). Florestan ou o sentido das coisas. São Paulo: Boitempo, p. I43-I56.

Bastos, Elide R. (I996). A questão racial e a questão nacional. In: Faleiros, Maria Izabel Leme \& Crespo, Regina Aida (orgs.). Humanismo e compromisso: ensaios sobre Octavio Ianni. São Paulo: Ed. Unesp, p. 79-99.

Bastos, Elide R. (1995). O negro antes e depois de Gilberto Freyre. Jornal da Tarde- Caderno de Sábado, São Paulo, p. 4, I8 de novembro.

Bastos, Elide R. (I99I). A questão social e a sociologia paulista. São Paulo em Perspectiva, 5/I, p. 3I-39.

Bastos, Elide R. (I 988) Um debate sobre o negro no Brasil. São Paulo em Perspectiva, I/5, p. 20-26.

Bastos, Elide R. (I987). A questão racial e a revolução burguesa. In: D'Incao, Maria Angela (org.). O saber militante: ensaios sobre Florestan Fernandes. São Paulo: Paz e Terra, p. I40-I50.

Bastos, Elide R. (s/d). Pensamento e sociedade: o efeito político das ideias. Texto para debate no Projeto Temático Linhagens do pensamento político-social brasileiro. São Paulo: Fapesp/Cedec (mimeo).

Botelho, André. (20I 2). Interpretações do Brasil e ciências sociais, um fio de Ariadne. Sinais Sociais, 7, p. 10-35.

Botelho, André. (2002). Aprendizado do Brasil: a nação em busca de seus portadores sociais. Campinas: Ed. Unicamp.

Giddens, Anthony. (2013). A constituição da sociedade. São Paulo: Martins Fontes.

Liedke Filho, Enno D. (I977). Teoria social e método na Escola da USP (I 954/1962). Dissertação de Mestrado. Universidade de Brasília. 
ARTIGO | ANTONIO BRASIL JR.

573

Luhmann, Niklas. (2007). La sociedad de la sociedad. México: Herder.

Mariosa, Duarcides. (2007). Florestan Fernandes e a sociologia como crítica dos processos sociais. Tese de Doutorado. Programa de Pós-Graduação em Sociologia/Unicamp.

Miceli, S. (200I). Intelectuais à brasileira. São Paulo: Companhia das Letras.

Pécaut, Daniel. (I990). Os intelectuais e a política no Brasil: entre o povo e a nação. São Paulo: Ática. 


\section{AS IDEIAS COMO FORÇAS SOCIAIS: SOBRE UMA AGENDA DE PESQUISA}

Resumo

Neste trabalho, analisamos os textos de Elide Rugai Bastos dedicados à chamada escola sociológica paulista, isto é, à produção sociológica que se organizou e se desdobrou a partir de Florestan Fernandes. Buscamos destacar as contribuições da autora para as pesquisas acerca do pensamento social no Brasil. Para tanto, mostraremos como a autora: (i) entende o processo de sistematização das ciências sociais no Brasil, bem como o papel ocupado por Freyre e por Fernandes neste processo; (ii) reconstrói as categorias analíticas presentes na produção sociológica de Fernandes e de seu grupo; e (iii) conecta esta tradição intelectual ao problema do lugar e dos efeitos das ideias na conformação da sociedade.

IDEAS AS SOCIAL FORCES:

\section{A RESEARCH AGENDA PROPOSAL}

Abstract

This article discusses Elide Rugai Bastos' contributions to the contemporary researches on Brazilian social thought. It analyzes her main texts on the so-called São Paulo sociological school, i. e., the sociological perspective based on Florestan Fernandes' work. Specifically, we focus on how Bastos: (i) understands the process of systematization of Brazilian social sciences, as well the role played by Freyre and Fernandes in this process; (ii) reconstructs the analytical categories that emerge from the sociology proposed by Fernandes and his group; and (iii) renovates this intellectual tradition with the discussion of the role of ideas in social change.
Palavras-chave:

Pensamento Social;

Elide Rugai Bastos;

Florestan Fernandes;

Intelectuais;

Ideias e sociedade.

Keywords:

Brazilian social thought;

Elide Rugai Bastos;

Florestan Fernandes;

Intellectuals;

Ideas and society. 